\title{
Polyarticular Neurogenic Heterotopic Ossification in a Spinal Cord Injury: A Case Report from Saudi Arabia
}

\author{
Taha Ali $^{1}$, Rouaa F. Mandurah ${ }^{2}$, Sami Ullah ${ }^{2}$ \\ 1. Physical Medicine and Rehabilitation, King Fahad Medical City, Riyadh, USA 2. Physical Medicine and Rehabilitation, \\ King Fahad Medical City, Riyadh, SAU
}

Corresponding author: Taha Ali, tahaali81@hotmail.com

\begin{abstract}
A 33-year-old male victim of a motor vehicle accident, who presented with a T12 (thoracic 12 vertebra) burst fracture (ISNCSCI T11 AIS-A: International Standards for Neurological Classification of Spinal Cord Injury T11 ASIA Impairment Scale), was admitted to a rehabilitation hospital. A stage-II left ischial pressure ulcer was also reported. An X-ray of the pelvis revealed bilateral neurogenic heterotopic ossification (NHO) in both hips and knees, which was further confirmed by TC-99m methylene diphosphonate (MDP) bone scintigraphy. Interventions included indomethacin and conservative management. Surgery was not preferred, as NHO was still immature. Moreover, patient transfer and lower body dressing were unaffected by $\mathrm{NHO}$. It is important to consider an early radiological screen in selected high-risk cases for $\mathrm{NHO}$, to minimize the risk of associated complications.
\end{abstract}

Received 01/27/2019

Review began 01/28/2019 Review ended 02/03/2019 Published 02/05/2019

() Copyright 2019

Ali et al. This is an open access article distributed under the terms of the Creative Commons Attribution License CC-BY 3.0., which permits unrestricted use, distribution, and reproduction in any medium, provided the original author and source are credited.
Categories: Physical Medicine \& Rehabilitation, Orthopedics, Trauma

Keywords: heterotopic ossification, spinal cord injury, traumatic brain injury, activities of daily living, bilateral hip joints, bilateral knee joints

\section{Introduction}

Spinal cord injury (SCI) is a neurological disorder that not only disrupts motor and sensory signaling across the injury site but also affects the functioning of the autonomic nervous system [1]. SCI often leads to disabilities that hinder the activities of daily living [2]. Huge efforts have been made by researchers in understanding the pathogenesis and early recognition and treatment of SCI; still, it remains a devastating disorder [3]. The incidence of traumatic SCI (TSCI) in Middle East countries is under-estimated, and the probable estimates are 15 TSCI per million per year [4]. The rate of traumatic SCI caused by land transport accidents in Saudi Arabia is reported to be 85\%, the highest in the world [5]. However, there is no data registry system available to collate the whole TSCI data in Saudi Arabia. Introducing a proper data registry system may help in closely knowing the status of TSCI etiology [6]. A recent study reported the prevalence of NHO in patients with TSCI to be $11 \%$ [7].

Additionally, it can be found in patients with hip surgery, burns, stroke, encephalopathy, and cerebral palsy or it can be hereditary, like osteodystrophy [8]. The most commonly affected joint is the hip but other locations include the knee, elbow, and shoulder [9]. People with SCI develop significant restriction in the range of motion (ROM) that interferes with mobility and the activities of daily living (ADLs) [2]. Bilateral hip and knee NHO following SCI is rare and has been rarely reported before in the literature.

\section{Case Presentation}

A 33-year-old male involved in a road traffic accident (MVA) in July 2016 was admitted to our hospital. He sustained a T12 burst fracture, thus requiring open reduction and internal fixation from T10-L1. As a result of SCI, he developed paraplegia (T11 AIS-A), a pressure injury, and double incontinence. Upon admission to the rehabilitation hospital, he was found to have a left ischial pressure ulcer (stage II). The pelvis X-ray showed bilaterally symmetrical NHO in both hips (Figure $1 A$ ) and knees (Figure $1 B$ ). Subsequently, TC-99m methylene diphosphonate (MDP) bone scintigraphy (Figure 2) showed findings compatible with NHO around both knees and hip joints bilaterally, and it appeared to be immature. He was managed conservatively and commenced on indomethacin. The surgical referral was not considered, as the NHO was not affecting the patient's transfers, lower body dressing, seating, skin, and other aspects of daily living. 


\section{Cureus}

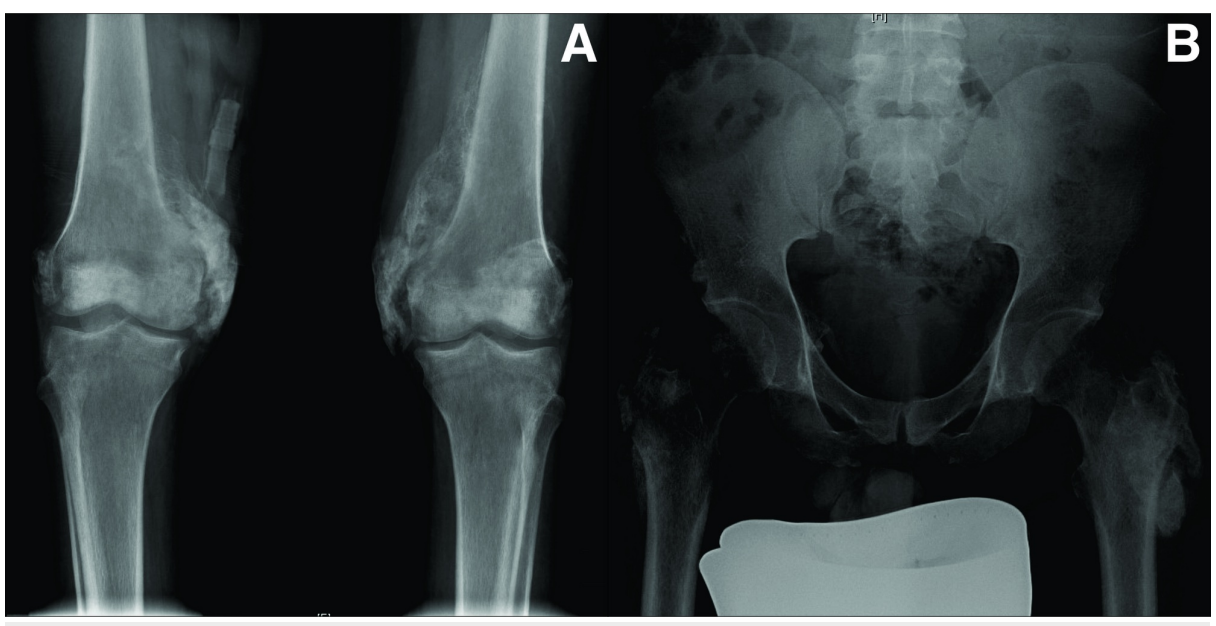

FIGURE 1: Mineralized bone visible around both knee and hip joints

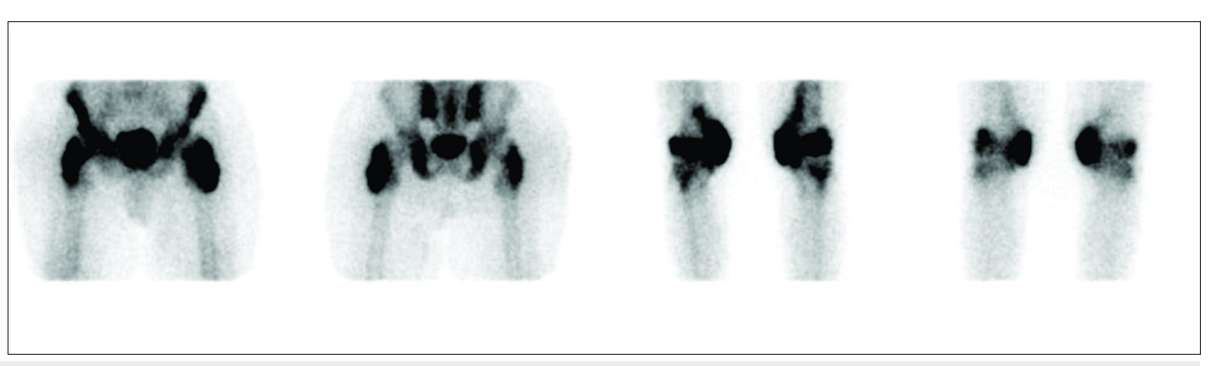

FIGURE 2: TC-99m MDP bone scintigraphy: increased intake around both hips and knees

MDP: methylene diphosphonate

\section{Discussion}

$\mathrm{NHO}$ is a frequent complication following SCI. It is defined as the abnormal formation of lamellar bone inside soft-tissue structures [10]. The exact pathophysiology of NHO is still not clear. However, multiple theories indicate disturbed neuronal activity along with prolonged immobilization, tissue hypoxia, and hypercalcemia. Thus, various humoral, neural, and local factors are held responsible behind the heterotopic ossification (HO) pathophysiology [11]. The usual clinical symptoms associated with HO include local joint pain, muscle pain, limited ROM, reduced motility of hip joint, and swelling. These may occur after three to 12 weeks of injury [12]. NHO is reported to grow more and completely evolve within two years after the injury [7].

In our case, clinical examination suspected $\mathrm{NHO}$ on admission to the spinal rehabilitation unit, and this was subsequently confirmed radiologically. The $\mathrm{NHO}$ was still immature at the time of admission to the rehabilitation unit. Thus, it is important to screen such cases earlier, to minimize the risk of complications associated with NHO. NHO usually occurs below the level of a central nervous system (CNS) lesion, and the complete transverse SCI goes parallel with the severity of NHO [11,13]. We started oral indomethacin, a nonsteroidal anti-inflammatory drug (NSAID), in our study patient. It has already been reported in previous studies that inflammation is a key factor involved in NHO development, and, therefore, some have hypothesized that the incidence and impact of NHO may be reduced with NSAIDs treatment. Some of the preliminary studies have reported the reduced occurrence of NHO in SCI patients treated with indomethacin [14-15]. For established NHO, surgical excision is considered as the only effective intervention available presently [16]. A recent systematic review of the surgical resection of SCI-induced $\mathrm{NHO}$ recommends earlier intervention once comorbid factors are controlled [16-17]. The surgical process is not preferred when nerves and blood vessels are entangled by ectopic bone. Around $20 \%$ of the cases of NHO are reported to relapse, with several other conditions like perioperative fracture and infections [18-19]. Therefore, we did not pursue the surgical option in this case. ADLs in patients with NHO can be affected secondary to pain, reduced ROM of the involved joint, poor posture, and the associated increased risk of a pressure injury. Prophylaxis includes the management of risk factors, such as spasticity, urinary tract infections (UTIs), decubitus ulcers, and deep vein thrombosis (DVT), which may reduce the risk of developing NHO [20]. It is recommended to cautiously follow the practice of consistently moving the large 
peripheral joints (gentle range of motion) after the injury. This helps in preventing muscle shortening and maintaining joint flexibility [11]. NHO in the bilateral hip joints and bilateral knee joints associated with SCI has never been reported previously and its pathogenesis is also unknown. This has further led to the lack of consensus on treatment modalities. As NHO affects ADL in patients with SCI, early diagnosis, prevention, and consensus on treatment modalities desperately need to be explored.

\section{Conclusions}

NHO in the bilateral hip joints and bilateral knee joints associated with SCI has never been reported previously and its pathogenesis is also unknown. This has further led to the lack of consensus on treatment modalities. As NHO affects ADL in patients with SCI, early diagnosis, prevention, and consensus on treatment modalities desperately need to be explored.

\section{Additional Information \\ Disclosures}

Human subjects: Consent was obtained by all participants in this study. Prof Omar H. Kasule (King Fahad Medical City) issued approval 17-170. This study has IRB approval with log and approval number. Conflicts of interest: In compliance with the ICMJE uniform disclosure form, all authors declare the following: Payment/services info: All authors have declared that no financial support was received from any organization for the submitted work. Financial relationships: All authors have declared that they have no financial relationships at present or within the previous three years with any organizations that might have an interest in the submitted work. Other relationships: All authors have declared that there are no other relationships or activities that could appear to have influenced the submitted work.

\section{Acknowledgements}

We would like to acknowledge Turacoz Healthcare Solutions (http://www.turacoz.com/) for the editing support.

\section{References}

1. Kirshblum SC, Burns SP, Biering-Sorensen F, et al.: International standards for neurological classification of spinal cord injury. J Spinal Cord Med. 2011, 34:547-554. 10.1179/107902611X13186000420242

2. Coura AS, Xavier de França IS, Enders BC, Barbosa ML, Silva Souza JR: Functional disability of adult individuals with spinal cord injury and its association with socio-demographic characteristics. Rev LatinoAm Enfermagem. 2012, 20:84-89. 10.1590/S0104-11692012000100012

3. Kwon BK, Tetzlaff W, Grauer JN, Beiner J, Vaccaro AR: Pathophysiology and pharmacologic treatment of acute spinal cord injury. Spine J. 2004, 4:451-464. 10.1016/j.spinee.2003.07.007

4. Lee BB, Cripps RA, Fitzharris M, Wing PC: The global map for traumatic spinal cord injury epidemiology: update 2011, global incidence rate. Spinal Cord. 2014, 52:110-116. 10.1038/sc.2012.158

5. Alshahri SS, Cripps RA, Lee BB, Al-Jadid MS: Traumatic spinal cord injury in Saudi Arabia: an epidemiological estimate from Riyadh. Spinal Cord. 2012, 50:882-884. 10.1038/sc.2012.65

6. Alshahri SS, Alshahri BS, Habtar A: Traumatic spinal cord injury (TSCI) in King Fahd Medical City, an epidemiological study. Neurol Neurother. 2016, 1:000106.

7. Reznik JE, Biros E, Marshall R, Jelbart M, Milanese S, Gordon S, Galea MP: Prevalence and risk-factors of neurogenic heterotopic ossification in traumatic spinal cord and traumatic brain injured patients admitted to specialised units in Australia. J Musculoskelet Neuronal Interact. 2014, 14:19-28.

8. Bossche LV, Vanderstraeten G: Heterotopic ossification: a review. J Rehabil Med. 2005, 37:129-136. 10.1080/16501970510027628

9. Brady RD, Shultz SR, McDonald SJ, O'Brien TJ: Neurological heterotopic ossification: current understanding and future directions. Bone. 2018, 109:35-42. 10.1016/j.bone.2017.05.015

10. Shehab D, Elgazzar AH, Collier BD: Heterotopic ossification. J Nucl Med. 2002, 43:346-353.

11. van Kuijk AA, Geurts AC, van Kuppevelt HJ: Neurogenic heterotopic ossification in spinal cord injury . Spinal Cord. 2002, 40:313-326. 10.1038/sj.sc.3101309

12. Schuetz P, Mueller B, Christ-Crain M, Dick W, Haas H: Amino-bisphosphonates in heterotopic ossification: first experience in five consecutive cases. Spinal Cord. 2005, 43:604-610. 10.1038/sj.sc.3101761

13. Sullivan MP, Torres JS, Mehta S, Ahn J: Heterotopic ossification after central nervous system trauma. Bone Joint Res. 2013, 2:51-57. 10.1302/2046-3758.23.2000152

14. Banovac K, Williams JM, Patrick LD, Levi A: Prevention of heterotopic ossification after spinal cord injury with COX-2 selective inhibitor (rofecoxib). Spinal Cord. 2004, 42:707-710. 10.1038/sj.sc.3101628

15. Banovac K, Williams JM, Patrick LD, Haniff YM: Prevention of heterotopic ossification after spinal cord injury with indomethacin. Spinal Cord. 2001, 39:370-374. 10.1038/sj.sc.3101166

16. Almangour W, Schnitzler A, Salga M, Debaud C, Denormandie P, Genêt F: Recurrence of heterotopic ossification after removal in patients with traumatic brain injury: a systematic review. Ann Phys Rehabil Med. 2016, 59:263-269. 10.1016/j.rehab.2016.03.009

17. Genêt F, Ruet A, Almangour W, Gatin L, Denormandie P, Schnitzler A: Beliefs relating to recurrence of heterotopic ossification following excision in patients with spinal cord injury: a review. Spinal Cord. 2015, 53:340-344. 10.1038/sc.2015.20

18. Cipriano CA, Pill SG, Keenan MA: Heterotopic ossification following traumatic brain injury and spinal cord injury. J Am Acad Orthop Surg. 2009, 17:689-697.

19. Chalidis B, Stengel D, Giannoudis PV: Early excision and late excision of heterotopic ossification after 


\section{Cureus}

traumatic brain injury are equivalent: a systematic review of the literature. J Neurotrauma. 2007, 24:16751686. 10.1089/neu.2007.0342

20. Cuccurullo SJ: Physical Medicine and Rehabilitation Board Review, 2nd Edition . Demos, New Jersey; 2010. 